\title{
Alfabetização científica e inclusão educacional: ensino de ciências para alunos com Transtorno do Espectro Autista
}

Marcella Fernandes Xavier ${ }^{1}$ Paloma Alinne Alves Rodrigues ${ }^{2}$

\begin{abstract}
Resumo:
Alfabetização Científica trata-se de uma estratégia de ensino que visa a auxiliar o aluno a compreender o mundo que o rodeia de modo a torná-lo um cidadão crítico. Por isso, torna-se interessante adotar essa estratégia desde os anos iniciais, assim como implementá-la em um contexto inclusivo. Por isso, o presente artigo tem por objetivo compartilhar os resultados obtidos por meio de uma investigação desenvolvida no âmbito do projeto de extensão "Práticas Inclusivas no Ensino de Ciências", do grupo de pesquisa "Núcleo de Estudos em Formação Docente, Tecnologias e Inclusão - NEFTI", na Universidade Federal de Itajubá. Para tanto, utilizou-se como referencial teórico Fourez (1995), Chassot (2000), Furió et al. (2010) e Sasseron (2008). A pesquisa possui uma abordagem qualitativa e configura-se como um estudo de caso. Além disso, utilizou-se como estratégia metodológica uma sequência didática de Ciências com um aluno que possuía Transtorno do Espectro Autista e Transtorno de Déficit de Atenção e Hiperatividade. Os resultados abordados possuem o intuito de promover uma reflexão sobre o benefício do uso de sequências didáticas para o ensino, a fim de minimizar as dificuldades de aprendizagem dos alunos com deficiência, ao relacionar os conteúdos a padrões de interesse do aluno.
\end{abstract}

\author{
Palavras-chave: \\ Alfabetização Científica. Autismo. Inclusão. Ensino de ciências. TEA.
}

\section{Scientific literacy and educational inclusion: scientific teaching for students with Autistic Spectrum Disorder}

\footnotetext{
Abstract:

Scientific Literacy is a teaching strategy that aims to help students understand the world around them to make them a critical citizen. Therefore, it's interesting to adopt this strategy from the early years,

1 Licenciada em Química pela UNIFEI, Universidade Federal de Itajubá (UNIFEI). E-mail: marcella.fxavier@gmail.com. ORCID iD: https://orcid.org/0000-0003-0817-717X.

2 Doutora em Educação pela USP, Universidade Federal de Itajubá (UNIFEI), professora do Instituto de Física e Química (IFQ) e coordenadora do grupo de pesquisa "Núcleo de Estudos em Formação Docente, Tecnologias e Inclusão - NEFTI". E-mail: palomaraap@unifei.edu.br. ORCID iD: https://orcid.org/0000-0001-9005-5627.
} 
as well as to implement it in an inclusive context. Therefore, this article objectives to share the results obtained through an investigation developed under the extension project "Inclusive Practices in Science Teaching", of the research group "Center for Studies in Teacher Training, Technologies and Inclusion - NEFTI", at the Federal University of Itajubá. For this purpose, was used as reference Fourez (1995), Chassot (2000), Furió et al. (2010) and Sasseron (2008). The research has a qualitative approach and is configured as a case study. Further, a didactic sequence of Science was used as a methodological strategy with a student who had Autistic Spectrum Disorder and Attention Deficit Hyperactivity Disorder. The results are intended to promote a reflection on the benefit of using didactic sequences for teaching, to minimize the learning difficulties of students with disabilities, by relating the contents to patterns of student interest.

\section{Keywords:}

ASD. Autism. Inclusion. Scientific Literacy. Science teaching.

\section{Alfabetización científica e inclusión educativa: enseñar ciencia a estudiantes con Trastorno del Espectro Autista}

\section{Resumen:}

La Alfabetización Científica es una estrategia de enseñanza que tiene como objetivo ayudar a los estudiantes a comprender el mundo que los rodea para convertirlos en ciudadanos críticos. Por tanto, es interesante adoptar esta estrategia desde los primeros años, así como implementarla en un contexto incluido. Por ello, este artículo tiene como objetivo compartir los resultados obtenidos mediante una investigación desarrollada en el ámbito del proyecto de extensión "Prácticas Inclusivas en la Enseñanza de las Ciencias", del grupo de investigación "Centro de Estudios en Formación Docente, Tecnologías e Inclusión - NEFTI", de la Universidad Federal de Itajubá. Para ello, se usó como referencia teórica Fourez (1995), Chassot (2000), Furió et al. (2010) y Sasseron (2008). La investigación tiene un enfoque cualitativo y se configura como un estudio de caso. Además, se utilizó una secuencia didáctica de Ciencias como estrategia metodológica con un alumno que presentaba Trastorno del Espectro Autista y Trastorno por Déficit de Atención con Hiperactividad. Los resultados pretenden promover una reflexión sobre el beneficio de utilizar secuencias didácticas para la docencia, con el fin de minimizar las dificultades de aprendizaje de los estudiantes con discapacidad, relacionando los contenidos con patrones de interés del estudiante.

\section{Palabras clave:}

Alfabetización Científica. Autismo. Enseñanza de la ciencia. Inclusión. TEA.

\section{Introdução}

A alfabetização está relacionada com o conhecimento ou saber excessivo conquistado pela prática, raciocínio ou reflexão ou pode ser considerada como um conjunto de conhecimentos fundados sobre um princípio certo. Tem-se que "alfabetizar" se trata do ensino da leitura e escrita e que "Ciência" é um conjunto de conhecimentos e saberes. Porém, quando se fala em "Alfabetização Científica" (AC), essa expressão assume um significado diferente da simples combinação dos conceitos isolados de suas palavras. Assim, é de extrema importância compreender a essência da expressão, para que seu significado e assimilação não sejam resumidos à simples união de seus sentidos isolados. É importante destacar que, o termo AC dialoga com a ideia de Paulo Freire (1999), de que a alfabetização é mais do que o simples psicológico e mecânico de técnicas de escrever e de ler, mas sim o domínio destas em termos conscientes. Isso implica uma autoformação que pode resultar em uma postura interferente do homem em seu contexto. 
O primeiro pesquisador a utilizar o termo "Scientific Literacy" foi Paul Hurd em seu livro Science Literacy: Its Meaning for American Schools, publicado em 1958. Mas, ao longo dos anos, pesquisadores como Fourez (1995), Chassot (2000) e Furió (2010), se aprofundaram na investigação sobre o que é a $\mathrm{AC}$ e sua importância e, com isso, o tema tem alcançado maior repercussão nos ambientes escolares, desde a formação de professores até sua atuação em sala de aula. Entretanto, é preciso compreender que a expressão "Alfabetização Científica" possui amplos significados, de acordo com diferentes autores. Para Fourez (1995), por exemplo, a expressão representa um tipo de capacidade ou de conhecimento e de saber o que no mundo técnico-científico, seria uma contraparte ao que foi a alfabetização no século passado. Para Chassot (2000), o termo representa um conjunto de conhecimentos que facilitariam aos homens e às mulheres fazerem uma leitura do mundo onde vivem. Para Furió et al. (2010), a AC é a possibilidade de que a maior parte da população possua conhecimentos científicos e tecnológicos necessários para se desenvolver na vida cotidiana, ajudar na resolução de problemas e nas necessidades de saúde e sobrevivência básica e tomar consciência das complexas relações entre a Ciência e a sociedade. Neste trabalho, fundamentado nos autores citados, considera-se a AC como uma forma de aprendizagem que possibilita ao indivíduo um melhor entendimento do mundo que o rodeia, de forma a compreender o porquê dos diversos fenômenos cotidianos com os quais possui contato, de modo a tornar-se um cidadão crítico, conforme salienta Sasseron (2008).

Dessa forma, nota-se a imprescindibilidade da escola possibilitar aos alunos a compreensão e o saber das Ciências, suas tecnologias e a relação de ambas com a sociedade como forma de prepará-los como cidadãos para o mundo. Para tanto, surge a necessidade de um ensino de Ciências que ofereça aos alunos não apenas as noções básicas de conceitos científicos, mas que propicie a oportunidade de criar e fazer Ciência, com base em problemas cotidianos na busca por condições para resolvê-los. Frente a tais conhecimentos sejam capazes de discutir essas informações, refletir sobre os impactos que podem representar e levar à sociedade e ao meio ambiente e, como resultado de tudo isso, posicionar-se criticamente frente ao tema.

Neste trabalho destaca-se a inclusão da AC desde o ensino infantil, que ela não deve contemplar apenas o ensino regular, mas também a educação inclusiva. Por outro lado, Vier e Silveira (2014) salientam que, apesar de se fazer cada vez mais presente no cotidiano escolar e compor inúmeras reflexões acadêmicas, a inclusão educacional da pessoa com deficiência ainda é um assunto controverso. Isso se deve ao fato das dificuldades enfrentadas pelas escolas em efetivar esse processo de modo a garantir a aprendizagem e o desenvolvimento do aluno. No entanto, é preciso compreender que a inclusão educacional é um processo que deve visar não apenas à inserção social do indivíduo, mas também o seu aprendizado.

Neste caminho, a Declaração de Salamanca (1994) certificou que as pessoas com deficiência passassem a ser vistas com maior dedicação ao recomendar que crianças e jovens tivessem acesso ao ensino regular, independentemente de suas necessidades educacionais, e que as escolas deveriam se adequar às suas especificidades. Contudo, com a Lei Brasileira de Inclusão (2015), tem-se um avanço substancial para a inclusão, não apenas ao modificar o conceito de deficiência, que passou a ser entendida como resultado da interação das barreiras impostas pelo meio com as limitações de natureza física, mental, intelectual e sensorial do indivíduo, e não mais como uma condição estática e biológica do mesmo, mas também por assegurar a autonomia e capacidade de que estes cidadãos tenham o direito de exercer funções civis igualmente às pessoas sem deficiência. No entanto, observa-se que ainda há um grande desafio em criar-se uma cultura inclusiva, ao tentar derrubar as barreiras existentes ao se falar sobre as capacidades e possibilidades das pessoas com deficiência, síndrome e/ou transtornos não somente na inclusão social, mas também na inclusão escolar.

Dessa maneira, a fim de facilitar a inclusão educacional de indivíduos com deficiência, tem-se a AC como um instrumento imprescindível ao ensino, especialmente para alunos com 
Transtorno do Espectro Autista (TEA). De acordo com o DSM-V (Manual de Diagnóstico e Estatística de Transtornos Mentais) é um transtorno do neurodesenvolvimento, caracterizado por defasagens na comunicação e interação, incluindo déficits na reciprocidade social, em comportamentos não verbais de comunicação e em habilidades para desenvolver, manter e compreender relacionamentos. Além dos déficits na comunicação social, o diagnóstico do TEA caracteriza-se pela presença de padrões restritos e repetitivos de comportamento, interesses ou atividades. É importante compreender que os alunos com TEA, também são considerados, conforme o Ministério da Educação (2008), alunos público-alvo da educação especial. Desse modo, este decreto atribui à educação especial o poder de promoção de uma escola democrática e inclusiva, com a finalidade de realizar adequações no sistema educativo para alunos com significativas limitações decorrentes de alterações funcionais e estruturais e das quais resultam dificuldades continuadas ao nível da comunicação, da aprendizagem, da autonomia, do relacionamento interpessoal e da participação social (LEAL, 2015).

Para tanto, é extremamente pertinente o estudo de novas metodologias de ensino que facilitem o processo de ensino-aprendizagem, inclusive os relacionados a AC para pessoas com deficiência, no intuito de minimizar suas defasagens e adaptar o ensino a suas especificidades. Assim, em meio às diversas metodologias e estruturas pedagógicas e didáticas possíveis, salienta-se neste trabalho o uso de "sequência didática". Essa estratégia didática possui a finalidade de explorar os conhecimentos científicos de forma mais profunda, para auxiliar o aluno a desenvolver seu conhecimento por meio de atividades pedagógicas diferenciadas e adaptadas, que estimulem o pensamento criativo e intuitivo do aluno, conforme salienta Zabala (1998). Destaca-se que a implementação de sequências didáticas para o ensino, não apenas de indivíduos público-alvo da educação especial, mas de todo e qualquer sujeito, apresenta grandes possibilidades de uso, porém trata-se de uma metodologia não tão presente em sala de aula. De acordo com Xavier, Silva e Rodrigues (2017), apesar do potencial pedagógico das sequências didáticas, é possível observar que não são todos os professores dos cursos de licenciatura que abordam essa estratégia, assim como não propiciam ao licenciando a construção de saberes relacionados à educação inclusiva. Dessa forma, o presente trabalho tem o objetivo de expor os resultados de uma pesquisa desenvolvida na Universidade Federal de Itajubá (UNIFEI) no âmbito do projeto "Práticas Inclusivas no Ensino de Ciências", que consistiu na elaboração e implementação de uma sequência didática de Ciências para um aluno com TEA que visava a aproximá-lo dos conceitos científicos, assim como iniciar o processo de sua AC no que concerne aos conteúdos de Química.

\section{Metodologia}

A fim de melhor explicitar o processo pelo qual aconteceu a pesquisa, a metodologia dividiu-se em três partes, sendo elas:

\section{Contexto e caracterização do sujeito da pesquisa}

A pesquisa foi desenvolvida no âmbito do projeto de extensão "Práticas Inclusivas no Ensino de Ciências", realizado pelo grupo de pesquisa "Núcleo de Estudos em Formação Docente, Tecnologias e Inclusão - NEFTI", na Universidade Federal de Itajubá - UNIFEI. Consiste em um projeto que visa a proporcionar a alunos de cursos de licenciatura em Química, Física, Biologia e Matemática a elaboração e implementação de sequências didáticas para alunos público-alvo da educação especial, de modo individual. Além disso, minimizar suas defasagens ao propiciar-lhes 
uma aprendizagem significativa, conforme ressalta Moreira (2012), em concordância com Ausubel, ao caracterizar como a interação entre conhecimentos prévios e novos, de modo que tais conhecimentos adquirem novos significados, com maior estabilidade cognitiva, com o intuito de que eles alcancem o ensino médio e o ensino superior (RUAS, 2017).

O sujeito para o qual a sequência foi desenvolvida tem seis anos de idade, encontrava-se em fase inicial de alfabetização e foi diagnosticado com TEA em grau leve e Transtorno de Déficit de Atenção e Hiperatividade (TDAH). O TDAH é caracterizado por um padrão persistente de desatenção e/ou hiperatividade-impulsividade que interfere no funcionamento e no desenvolvimento do sujeito. Há evidências de que os sintomas interferem no funcionamento social, acadêmico ou profissional ou de que reduzem sua qualidade. Nesse caso, o aluno para o qual a sequência foi desenvolvida não apresenta significativas particularidades do TEA, todavia apresenta expressivas características relacionadas ao TDAH como sua extrema hiperatividade e dificuldade de concentração em uma mesma atividade por mais de alguns minutos.

\section{Sequência Didática "A fantástica aventura da respiração" 3}

Com o intuito de tornar a aprendizagem significativa, optou-se por relacionar os conteúdos a serem ensinados a um padrão de interesse do aluno, sendo este os dinossauros. Para tanto, buscou-se, na sequência, destacar as diferenças entre a respiração humana e a dos dinossauros voadores, ressaltando os gases presentes na respiração. Assim, tendo em vista que o aluno estava em processo de alfabetização, ainda não sabia ler ou escrever, optou-se por atividades mais lúdicas.

A primeira atividade consistiu em propiciar ao aluno uma compreensão sobre o que é o ar e sua importância. Com a palavra ar escrita no quadro, a professora questionou sobre o que era e, a seguir, explicou, de uma forma dinâmica, seu significado e sua importância. A fim de mostrar suas diversas formas de maneira divertida, mostrou-se o vídeo da música $O$ ar ( $O$ vento), de Vinícius de Moraes, e, para finalizar, foi realizado o experimento Verificando se o ar existe mesmo, no qual, por meio do uso de uma bacia com água, a metade superior de uma garrafa pet e uma bexiga acoplada ao bico da garrafa, o aluno pressionava a garrafa com a bexiga na bacia com água, verificava se a bexiga encheria ou não, de modo a concluir a real existência do ar.

Já a segunda atividade, abarcou a construção dos saberes sobre como acontece a respiração e quais os gases envolvidos. Para tanto, foi efetuada uma revisão do conteúdo da aula anterior, por meio de perguntas simples. Além disso, utilizou-se a animação online Sistema Respiratório, do Portal do Professor, no qual foram demonstradas a respiração humana e as partes do organismo envolvidas e, com base na animação, foi explicado em detalhes como ocorre a respiração, e, em seguida, com um desenho, os gases envolvidos no processo respiratório.

$\mathrm{Na}$ terceira atividade, foi realizada novamente uma revisão da animação apresentada na aula anterior, seguida da exibição de uma imagem do sistema respiratório humano, a fim de que o aluno comparasse com as imagens mostradas a seguir, relativas ao sistema respiratório dos pássaros, que, consequentemente, é semelhante à dos dinossauros voadores, padrão de interesse apresentado pelo aluno. Concluídas as observações do aluno, foi realizada uma explicação sobre as diferenças entre ambos os sistemas. Em seguida, o aluno realizou uma atividade com diversas partes do corpo participantes da respiração humana, visando a que ele indicasse qual parte estava incorreta.

Para finalizar a sequência, foi realizada uma avaliação, na qual a professora questionou o aluno acerca de todo o conteúdo trabalhado, como: O que é o ar e qual sua importância? e Quais

3 A sequência didática desenvolvida para este aluno no projeto "Práticas Inclusivas no Ensino de Ciências" encontra-se disponível para download no site www.nefti.com.br na opção "Produções". 
gases participam da respiração dos seres humanos?. Feito isso, mostrou-se uma imagem de um pulmão na garrafa e junto elaborou-se o experimento demonstrativo da respiração humana, para que o aluno a explicasse e, a seguir, fizesse um comparativo entre as respirações humana, dos pássaros e dos dinossauros voadores.

\section{Aspectos Metodológicos}

Este trabalho é uma pesquisa qualitativa, pois privilegia a análise de microprocessos, por meio do estudo das ações sociais individuais e grupais, realizando um exame intensivo dos dados e caracterizada pela heterodoxia no momento da análise (MARTINS, 2004). Segundo Carvalho (2016), apesar de uma metodologia de pesquisa não se resumir à coleta de dados, esta é a sua principal função, porque a estrutura metodológica de uma pesquisa visa a cercar a coleta de dados de todos os cuidados para que esses respondam, com a maior confiabilidade e precisão possível, às questões levantadas. Assim, conforme Lüdke e André (1986) a pesquisa qualitativa tem o ambiente natural como sua fonte direta de dados e o pesquisador como seu principal instrumento. Sua preocupação com o processo é muito maior do que com o produto e a análise dos dados tende a seguir um processo indutivo. Desse modo, sabe-se que essa forma de pesquisa abriga diversas estratégias metodológicas, sendo as principais a pesquisa etnográfica e o estudo de caso. Na pesquisa etnográfica, descreve-se um sistema de significados culturais de um determinado grupo, de modo que um estudo replicado sobre questões educacionais que utilize a etnografia deve refletir sobre o processo de ensino-aprendizagem, em um contexto sociocultural mais amplo. O estudo de caso visa a focalizar em um único caso, normalmente aplicado quando o pesquisador tem interesse em compreender uma situação singular (LÜDKE; ANDRÉ, 1986).

Desse modo, a pesquisa caracteriza-se como um estudo de caso. Para tanto, optou-se pelo uso da entrevista não estruturada com o sujeito da pesquisa, mediante a autorização dos pais. De acordo com Marconi e Lakatos (2007), nesse tipo de entrevista, são utilizadas perguntas abertas que podem ser respondidas dentro de uma conversação informal. Esse instrumento de pesquisa apresenta diversas vantagens e entre elas destaca-se o fato do entrevistado, que não sabe ler ou escrever, ter condições de responder às indagações de forma verbal. Além disso, pode ser utilizada com todos os segmentos da população e apresenta grande flexibilidade, pois o entrevistador tem a possibilidade de repetir ou esclarecer perguntas ou reformulá-las. Todavia, também apresenta limitações como possíveis dificuldades de expressão e comunicação de ambas as partes, incompreensão do questionamento feito, e depende da disposição do entrevistador para fornecer as informações necessárias.

Marconi e Lakatos (2007) ponderam que a entrevista não estruturada apresenta três modalidades: focalizada, clínica e não dirigida. Nesta pesquisa, utilizou-se a entrevista focalizada, na qual há um roteiro de tópicos relativos ao problema que se vai estudar e o entrevistador tem liberdade de fazer as perguntas que quiser: sonda razões e motivos, presta esclarecimentos, não obedecendo, a rigor, a uma estrutura formal. Para isso, são necessárias habilidade e perspicácia por parte do entrevistador.

Para registrar o diálogo, optou-se pela gravação em áudio, que foi gravado após a realização do experimento da construção do pulmão na garrafa relativo à atividade de avaliação da sequência didática. A partir disso, todos os dados foram transcritos, de acordo com a fala do entrevistado, pelo próprio pesquisador. Ressalta-se que as transcrições devem ser totalmente fiéis às falas a que correspondem, com a substituição de termos por sinônimos sendo terminantemente proibida. 
É imprescindível salientar que todas as atividades da "sequência didática", realizadas durante os encontros semanais com o sujeito, foram relatadas em um portfólio on-line. Hernández (1998) argumenta que o portfólio é um continente de diferentes classes de documentos (notas pessoais, experiências de aula, trabalhos pontuais, controle de aprendizagem, conexões com outros temas fora da escola, representações visuais etc.). Esse recurso proporciona evidências do conhecimento que foi construído, das estratégias utilizadas e da disposição de quem o elabora em continuar aprendendo. A seguir, têm-se a análise dos conteúdos coletados por meio da gravação de áudio realizada na avaliação da sequência desenvolvida, a fim de verificar a aproximação do aluno com os conceitos trabalhados.

\section{Resultados}

Baseado na gravação de áudio resultante da avaliação, tem-se que, ao questionar o aluno sobre como acontecia a respiração, foi obtida a seguinte resposta: "A respiração tem os pelinhos do nariz que seguram a sujeira do ar. Aí a gente respira o gás oxigênio e gás carbônico, que vai pra traqueia e vai pros pulmões e sai pela boca." (Aluno, resposta obtida por meio de entrevista oral).

Ao considerar comportamentos prévios do aluno, observou-se que, apesar de ele saber a ordem correta dos fatos, demonstrou falta de interesse para explicar os conteúdos da forma correta, devido à falta de estímulo visual. Desse modo, a professora pediu que o aluno explicasse na ordem correta como acontecia a respiração humana, mas, nesse segundo momento, utilizando o "pulmão na garrafa". Sendo assim o aluno respondeu que:

O ar entra pelo nariz, aí a sujeira dele fica nos pelinhos, aí ele passa pela traqueia e chega nos pulmões, lá fica o gás oxigênio e sai o gás carbônico, pela boca e assim, acontece a nossa respiração, igual mostra o pulmão na garrafa. (Aluno, resposta obtida por meio de entrevista oral).

Feito isso, o aluno foi interrogado se a respiração humana, explicada por ele, era parecida com à dos pássaros e a qual outra ela se assemelhava: "Não, porque os passarinhos têm o pulmão e os sacos de ar [...] é parecida com a dos dinossauros que voam, que também têm os quatro sacos aéreos", foi a resposta obtida oralmente a partir da resposta do aluno.

Ao observar seu desenvolvimento desde sua primeira aula "diagnóstica" até sua avaliação, é possível inferir que o aluno não apenas assimilou os conteúdos, obtendo uma aprendizagem significativa, como também compreendeu melhor o motivo das aulas e de sua presença nestes momentos com a professora. Ainda assim, apresentar em diversas ocasiões uma conduta não condizente com o comportamento esperado em sala de aula, de modo que na maior parte das aulas, tornou-se necessária uma postura rígida da professora, assim como um esquema de troca com o aluno, no qual se ele concluísse a atividade solicitada de forma correta, poderia ao fim brincar um pouco, pois era o maior desejo dos alunos nestes momentos.

Ressalta-se que ao compreender como acontecia a respiração humana, bem como à dos pássaros, semelhante à dos dinossauros voadores, o aluno não se contentou em guardar o conhecimento para si, de modo que seu pai relatou que, a partir disso, o aluno passou a explicar para qualquer pessoa com quem conversasse o conteúdo aprendido, tanto em relação aos dinossauros, quanto sobre o modo como acontece a respiração humana, explicando de modo detalhado. Sobressai-se ainda o fato de que o aluno, que, ao iniciar as aulas sabia apenas escrever seu nome, devido à memorização, aprendeu a ler e escrever as palavras ar, oxigênio e gás carbônico, como demonstram as figuras a seguir. 
Figura 1: Palavras escritas pelo aluno ao longo da sequência

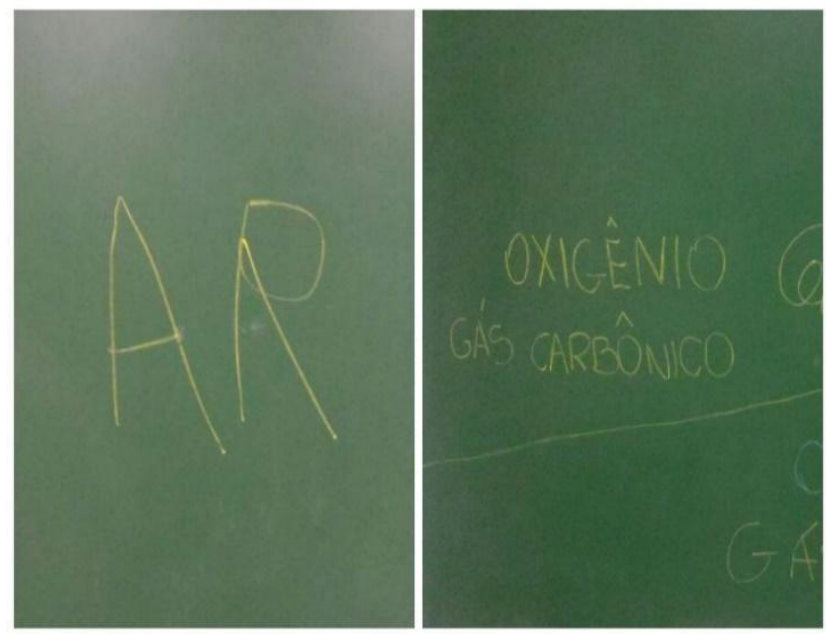

Fonte: Figura elaborada pelas autoras.

\section{Figura 2: Experimento "Pulmão na garrafa"}

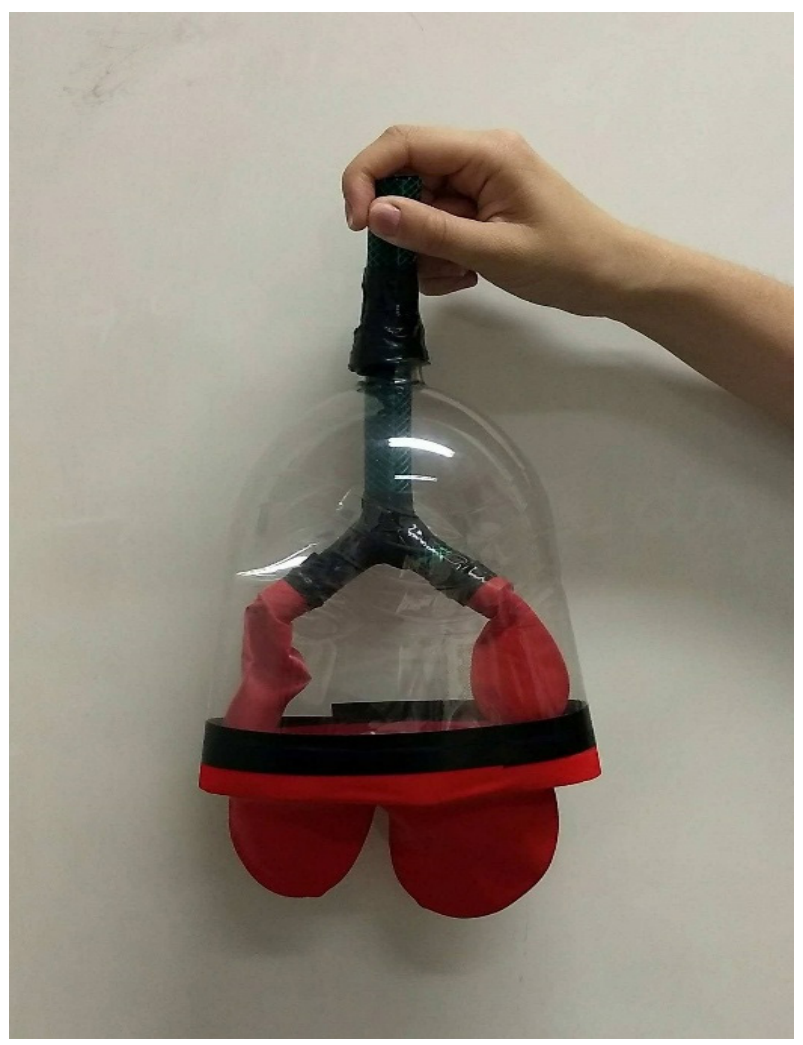

Fonte: Figura elaborada pelas autoras.

Ao analisar a implementação da sequência didática, assim como sua avaliação, considera-se que o sujeito assimilou o conteúdo ensinado. Diante disso, a nosso ver, é possível considerar que o mesmo foi aproximado da Alfabetização Científica, pois considera-se dado o início da AC quando o sujeito utiliza de conceitos científicos para explicar fatos cotidianos e é capaz de agregar valor ao conteúdo aprendido, ao reconhecer que as Ciências estão presentes em todos os âmbitos da vida humana e ser capaz, não apenas de reconhecer conceitos, teorias e hipóteses científicas, mas 
aplicá-las ao seu cotidiano e apreciar a estimulação intelectual que essas Ciências suscitam. Dessa forma, considera-se que o processo de alfabetização científica do aluno em questão foi iniciado efetivamente, ao observar que o aluno, durante o desenvolvimento e a conclusão da sequência, foi capaz, muitas vezes, de chegar às constatações corretas acerca do conteúdo por conta própria, bem como conseguiu associar o conteúdo às suas vivências.

Analisa-se também a eficácia da implementação do conteúdo abordado através de sequências didáticas, visto que essa estratégia de ensino permite a abordagem dos conceitos de forma aprofundada e permite maior flexibilidade em relação ao planejamento das aulas do que os planos de aula, mais comumente utilizados para o ensino, além das sequências didáticas ofertarem maior liberdade criativa ao professor e ao aluno.

\section{Conclusões}

Para estimular a aprendizagem de alunos com deficiência, síndromes e/ou transtornos, considera-se de extrema importância que os professores estejam atentos às individualidades de seus alunos, para que assim busquem adaptar suas metodologias de ensino, de modo a atender suas singularidades e auxiliá-los a desenvolver ao máximo suas potencialidades.

Dessa forma, apresenta-se o uso de sequências didáticas como uma metodologia eficaz para o ensino de Ciências para alunos com TEA e TDAH, devido à sua flexibilidade nos planejamentos, de acordo com a aprendizagem do aluno, e seu potencial de aprofundamento de conceitos e liberdade criativa para os conteúdos. Assim, é possível aprimorar as aptidões do sujeito, desenvolver suas potencialidades e minimizar suas defasagens, ao priorizar um ensino não focado em suas dificuldades, mas sim em suas especificidades. Portanto, a adoção de novas metodologias de aprendizagem, como a implementação de sequências didáticas para o Ensino Inclusivo, torna viável uma reestruturação necessária na forma de ensino convencional trabalhada em salas de aula, pois propõe um modelo didático aplicável à cadência de cada aluno em suas particularidades.

Enfim, sobressai-se principalmente a importância da Alfabetização Científica aos sujeitos público-alvo da educação especial, não apenas a fim de que estes sejam apresentados às Ciências e suas genialidades desde pequenos, mas, sim, pois nota-se que a proximidade da AC com o aluno com TEA, propicia que o mesmo tenha uma melhor compreensão sobre o porquê dos acontecimentos que o rodeiam, bem como o instiga a levantar hipóteses sobre tais fatos de modo a incentivá-lo na busca de mais conhecimento e a formar seu pensamento crítico desde a infância.

\section{Referências}

ASSOCIAÇÃO AMERICANA DE PSIQUIATRIA. DSM-V - Manual diagnóstico e estatístico de transtornos mentais. Porto Alegre: Artmed, 2014. p. 992.

BARDIN, Laurence. Análise de Conteúdo. Lisboa: Edições 70, 1977.

BRASIL. Lei Brasileira de Inclusão da Pessoa com Deficiência. LEI No 13.146, Brasília, DF, 6 de julho de 2015, 194º da Independência e $127^{\circ}$ da República, 2015.

CARVALHO, Anna Maria Pessoa de. Uma metodologia de pesquisa para estudar os processos de ensino e aprendizagem em salas de aula. In: A pesquisa em ensino de ciências no Brasil e suas metodologias [S.l: s.n.], 2006.

CHASSOT, Attico. Alfabetização científica: questões e desafios para a educação. 1. ed. Ijuí: Editora Unijuí, 2000. 
DECLARAÇÃO DE SALAMANCA. Sobre Princípios, Políticas e Práticas na Área das Necessidades Educativas Especiais. Salamanca, 10 de junho de 1994.

FOUREZ, Gérard. Construção das Ciências: introdução à filosofia e à ética das ciências. São Paulo: Editora da Universidade Estadual Paulista, 1995.

FREIRE, Paulo. Educação como prática da liberdade. 23. ed. Rio de Janeiro: Paz e Terra, 1999.

FURIÓ, Carles; VILCHES, Amparo; GUISASOLA, Jenaro; ROMO, Victor. Finalidades de La Enseñanza de Lãs Ciências en La Secundaria Obligatoria. Enseñanza de lãs ciências. , v. 19, n. 3, p. 365-76, 2021. Disponível em: <https://raco.cat/ index.php/Ensenanza/article/view/21756>. Acesso em: 17 jul. 2021.

HERNÁNDEZ, Fernando. Transgressão e mudança na educação: os projetos de trabalho. 1. ed. Porto Alegre: Artmed, 1998.

HURD, Paul. Science Literacy: Its Meaning for American Schools. Educational Leadership. Outubro, 1958. Disponível em: $<$ https://silo.tips/download/what-kind-of-education>. Acesso em: 18 jul. 2021.

LEAL, Ana Catarina Travessa. Contributos para o desenvolvimento de aplicações destinadas a crianças com perturbação do espectro do autismo. 2015. Dissertação (Mestrado em Ciências da Fala e da Audição) - Universidade de Aveiro, Portugal, 2015. Disponível em: <https://goo.gl/qiKcP2>. Acesso em: 12 nov. 2020.

LÜDKE, Menga; ANDRÉ, Marli E. D. A. Pesquisa em Educação: Abordagens Qualitativas - Temas Básicos de Educação e Ensino. São Paulo: Editora Pedagógica e Universitária LTDA, 1986.

MARCONI, Marina de Andrade; LAKATOS, Eva Maria. Técnicas de Pesquisa. 6. ed. São Paulo: Editora Atlas S.A., 2007.

MARTINS, Heloisa Helena T. de Souza. Metodologia qualitativa de pesquisa. Educação e Pesquisa. São Paulo, v. 30, n. 2, p. 289-300, 2004.

MEC. SECADI. Política Nacional de Educação Especial na perspectiva da Educação Inclusiva, 2008. Disponível em: $<$ https://goo.gl/M2xWbv>. Acesso em: 12 nov. 2020.

MORAES, Vinícius de. O ar (O vento). Universal Music Ltda, 1981. Disponível em: <https://www.youtube.com/watch? $\mathrm{v}=\mathrm{jAI} 4 \mathrm{R} 01 \mathrm{dLl} 8>$. Acesso em: 18 jul. 2021.

MOREIRA, Marco Antônio. O que é afinal aprendizagem significativa? Revista cultural La Laguna Espanha, 2012. Disponível em: <http://moreira.if.ufrgs.br/oqueeafinal.pdf >. Acesso em: 18 jul. 2021.

PORTAL DO PROFESSOR. Sistema Respiratório. Disponível em: <http://portaldoprofessor.mec.gov.br/fichaTecnica. html?id=11013>. Acesso em: 18 jul. 2021.

RUAS, Paloma Alinne Alves Rodrigues. Práticas Inclusivas no Ensino de Ciências. Experiências docentes em licenciaturas. São Paulo: Fundação Carlos Chagas - Prêmio Rubens Murillo Marques, v. 53, p. 133-147, 2017.

SASSERON, Lúcia Helena; CARVALHO, Anna Maria Pessoa de. Almejando a alfabetização científica no Ensino Fundamental: a proposição e a procura de indicadores do processo. Investigações em Ensino de Ciências. v. 13, n. 3, p. 333-352, 2008.

VIER, Rejane Fernandes da Silva. Alfabetização científica e tecnológica: os primeiros passos para inclusão educacional. Anais SETEPE. Campina Grande, n. 5, 2014. Disponível em: <https://editorarealize.com.br/artigo/visualizar/8092>. Acesso em: 18 jul. 2021.

XAVIER, Marcella Fernandes; SILVA, Bruno Yuri Diogo; RODRIGUES, Paloma Alinne Alves. Ensino de Ciências inclusivo para alunos com Transtorno do Espectro Autista e o uso de Sequências Didáticas. Anais XI ENPEC, 11. ed., 2017, Florianópolis. Disponível em: <https://goo.gl/xLxYu3>. Acesso em 24 set. 2020.

ZABALA, Antoni. A prática educativa: como ensinar. Porto Alegre: Artmed, 1998.

Data de submissão: 15/05/2021

Data de aceite: $23 / 08 / 2021$ 